\title{
Successful Treatment of PFAPA (Periodic Fever, Aphthous Stomatitis, Pharyngitis, and Adenitis) Syndrome with Shinbuto*
}

\author{
Yuichirou Tsuji\#, Chitose Karasawa \\ Department of Pediatrics, Tokyo Takanawa Hospital, Tokyo, Japan \\ Email: "yuitsuji@ybb.ne.jp
}

Received 2 September 2014; revised 1 October 2014; accepted 29 October 2014

Copyright (C) 2014 by authors and Scientific Research Publishing Inc.

This work is licensed under the Creative Commons Attribution International License (CC BY). http://creativecommons.org/licenses/by/4.0/

c) (i) Open Access

\begin{abstract}
Periodic fever with aphthous stomatitis, pharyngitis, and adenitis (PFAPA) syndrome is an autoimmune disorder and the most common disorder characterized by periodic fever in children. A male patient has been followed up from 11 months to 10 years of age because of repeated high fever. We prescribed antifebriles and antibiotics for each febrile episode without a beneficial effect to him each time. He required several days of rest at home to recover from each episode. During his most recent febrile episode at 10 years of age, we prescribed $5.0 \mathrm{~g}$ of shinbuto (TJ-30; Tsumura Co., Tokyo, Japan). His fever resolved the next day and he was able to attend school. His growth and development are normal. Shinbuto had a therapeutic effect in this patient with PFAPA syndrome and may be useful in this condition.
\end{abstract}

\section{Keywords}

Periodic Fever, Aphthous, PFAPA Syndrome, Shinbuto

\section{Introduction}

Periodic fever with aphthous stomatitis, pharyngitis, and adenitis (PFAPA) syndrome is the most common periodic fever syndrome in children. PFAPA was first reported by Marshall et al., 1987 in 12 pediatric patients [1].

PFAPA syndrome is characterized by periodic episodes of high fever lasting several days and recurring regularly every 1 to 3 months; the fever is often associated with aphthous stomatitis, pharyngitis, and adenitis. The

*Shinbuto, a traditional Japanese herbal medicine, may be efficacious for PFAPA syndrome. By shortening the duration of symptoms of PFAPA syndrome, it could improve the patient's quality of life.

${ }^{\#}$ Corresponding author.

How to cite this paper: Tsuji, Y. and Karasawa, C. (2014) Successful Treatment of PFAPA (Periodic Fever, Aphthous Stomatitis, Pharyngitis, and Adenitis) Syndrome with Shinbuto. International Journal of Clinical Medicine, 5, $1261-1264$. 
etiology of PFAPA syndrome is still unknown. The treatment of this syndrome has not yet been established but some treatments have been reported. Marshall et al., 1987 reported that prednisone therapy was successful [1]. Abramson et al., 1989 reported that tonsillectomy with adenoidectomy resulted in dramatic improvement [2]. Renko et al., 2007 also reported that tonsillectomy can be offered as an effective treatment for children with this unusual syndrome [3]. However, Victoria et al., 2011 reported that most patients with PFAPA experienced spontaneous symptom resolution with long-term follow-up [4]. We prescribed shinbuto to a 10-years-old boy with PFAPA syndrome and were able to reduce the duration of his symptoms. We report here the case of a male with PFAPA syndrome who had responded to treatment with shinbuto.

\section{Case Report}

A 1-year-old boy presented to our hospital because of a persistent fever of 4 days duration. His throat was slightly red, his breath sounds were normal and his cervical lymph nodes were slightly palpable; there were no other abnormalities on his physical examination. His previous medical history included tinea corporis at 10 month of age. The medical histories of his parents and sister were unremarkable for autoimmune and infectious diseases. The patient's fever persisted for 10 days. We prescribed oral cephems, but they did not reduce his fever. Ten days later, his temperature returned to normal range naturally. So, we did not perform any blood tests or radiographs at this time.

The patient's second episode occurred at the age of 20 months. We performed a chest radiograph and rapid antigen test for Streptococcus A; the results of both were normal. The patient's fever persisted for 6 days. After this episode, he experienced several episodes of persistent fever every year. In these episodes, he recovered naturally without complication. His asymptomatic intervals between episodes were about 30 to 60 days in duration. His physical and mental development was normal.

The patient's first complete blood count (CBC) was performed at 5 years of age with the following results; white blood cells count 16,100/ $\mu \mathrm{L}$ (differential count: neutrophils, $71.5 \%$; lymphocytes, $19.2 \%$; monocytes, 8.6\%; eosinophils, $0.1 \%$; basophils, $0.6 \%$ ); hemoglobin, $13.6 \mathrm{~g} / \mathrm{dL}$; platelets, $30.2 \times 10^{4} \mu \mathrm{L}^{-1}$; erythrocyte sedimentation rate, $47 \mathrm{~mm} / \mathrm{h}$; C-reactive protein, $5.4 \mathrm{mg} / \mathrm{dL}$. The findings from immunological testing were IgG, $1132 \mathrm{mg} / \mathrm{dL}$, IgA, $154 \mathrm{mg} / \mathrm{dL}$, IgM, $55 \mathrm{mg} / \mathrm{dL}$, C3, $141.3 \mathrm{mg} / \mathrm{dL}, \mathrm{C} 4,52.8 \mathrm{mg} / \mathrm{dL}, \mathrm{CH}_{50}, 57.0 \mathrm{mg} / \mathrm{dL}$, ANA 8.1 $\log \mathrm{IU} / \mathrm{mL}$, anti-DNA antibody $<2.0 \mathrm{IU} / \mathrm{mL}$. Biochemical laboratory results were all within the normal range for the patient's age. The culture results from throat, urine, and fecal samples were all negative. No abnormalities were found on urinalysis. Rapid antigen detection tests, including those for mycoplasma, adenovirus, and group A Streptococcus, were negative repeatedly. His physical and laboratory findings did not show evidence of a specific infectious disease, malignant tumor or immune disease. His X-ray examinations and sonography showed no abnormality.

None of the prescribed antibiotics including penicillins, cephems, macrolides, and quinolones had a therapeutic effect during any episode. However, he recovered from all episodes without complications.

On October 2013, he presented with a fever of 3 days. We prescribed shinbuto (TJ-30) for the first time. After only 2 doses of shinbuto, his temperature the next day was normal, $36.0^{\circ} \mathrm{C}$. In subsequent episodes, his fever has resolved with shinbuto except when he had an influenza type A infection.

\section{Discussion}

We diagnosed our patient with PFAPA syndrome based on the specific diagnostic criteria proposed by Victoria et $a l$. [4]. The patient had the following symptoms compliant with the diagnostic criteria: Regularly recurring fevers $\left(>38.3^{\circ} \mathrm{C}\right)$, with an early age of onset; constitutional symptoms in the absence of upper respiratory infection with at least one symptom being aphthous stomatitis, cervical lymphadenitis or pharyngitis; exclusion of cyclic neutropenia and other intermittent fever syndromes on the basis of history or laboratory test results; asymptomatic intervals between episodes; and normal growth and development.

Victoria et al. reported that most patients with PFAPA experience spontaneous symptom resolution without long-term sequelae; those patients with persistent symptoms, i.e., without spontaneous symptom resolution, had episodes of shorter duration and reduced frequency [4].

The elusiveness of the etiology of PFAPA syndrome has inevitably led to treatment uncertainties. Nonetheless, some treatments have been tried. Garavello et al. reported that the most effective treatment is corticosteroid therapy, which is associated with cessation of the fever cycle within 12 - $24 \mathrm{~h}$ [5]. Stojanov et al. suggested that 
the syndrome results from a disturbance of the immune response with continuous pro-inflammatory response that occurs both during and between febrile attacks [6]. The reason why corticosteroid therapy succeeds may be a reduction in cytokines. Furthermore, Garavello et al. suggested that tonsillectomy should be considered when symptoms markedly interfered with the child's quality of life and medical treatment failed [5]. On the other hand, Peridis et al. reported that tonsillectomy is an effective treatment for PFAPA syndrome [7].

Yamaguchi reported that herbal medicine treatment is effective for PFAPA syndrome and reported a case successfully treated with herbal therapy [8].

Ishii reported that shinbuto is very effective in treating acute infections in children [9]. She prescribed shinbuto to the 144 patients who had not been getting worse or had not recovered quickly from acute infections and found that shinbuto was effective in $86 \%$ without any adverse effects.

Shinbuto is one of the 148 Kampo extract preparations covered by Japan's National Health Insurance Program. Shinbuto contains Aconiti tuber (processed aconite root), Zingiberis rhizome (ginger), and Atractylodis lancea rhizome. Shinbuto increases metabolism, improves circulation, and warms the body. It is thought that these effects improve an immunodeficient state.

Our patient was not treated with predonisolone or cimetidine, which might have changed the course of his illness. In the future, we will consider these medications and if ineffective, we would then consider adenotonsillectomy.

In general, most patients with PFAPA syndrome experience spontaneous symptom resolution with no longterm sequelae. Now that our patient has reached 10 years of age and has not had an episode of persistent fever for about 1 year, it seems very unlikely that his remission occurred by chance. We plan to continue to follow up with him carefully.

\section{Summary}

It is thought that the medication of shinbuto is one of the therapy methods on PFAPA syndrome.

\section{Consent}

All authors declare that written informed consent was obtained (in Japanese) from the patient's parents for publication of this report.

\section{Ethics Approval}

This report was written with the permission of the Tokyo Takanawa Hospital Ethics Committee, which includes school teachers and a lawyer.

\section{Conflict of Interests}

All authors declare that they have no conflicts of interest related to this report.

\section{Acknowledgements}

The authors thank Ranko Mori for the suggestion of shinbuto therapy.

\section{References}

[1] Marshall, G.S., Edwarde, K.M., Butler, J. and Lawton, A.R. (1987) Syndrome of Periodic Fever, Pharyngitis, and Aphthous Stomatitis. The Journal of Pediatrics, 110, 43-46. http://dx.doi.org/10.1016/S0022-3476(87)80285-8

[2] Abramson, J.S., Givner, L.B. and Thompson, J.N. (1989) Possible Role of Tonsillectomy and Adenoidectomy in Children with Recurrent Fever and Tonsillopharyngitis. The Pediatric Infectious Disease Journal, 8, 119-120.

[3] Renko, M., Salo, E., Putto-Lauria, A., Saxen, H., Mattila, P.S., Luotonen, J., Ruuskanen, O. and Uhari, M. (2007) A Randomized, Controlled Trial of Tonsillectomy in Periodic Fever, Aphthous Stomatitis, Pharyngitis, and Adenitis Syndrome. The Journal of Pediatrics, 151, 289-292. http://dx.doi.org/10.1016/j.jpeds.2007.03.015

[4] Victoria, M., Wurster, V.M., Carlucci, J.G., Feder, H.M. and Edwards, K.M. (2011) Long-Term Follow-Up of Children with Periodic Fever, Aphthous Stomatitis, Pharyngitis, and Cervical Adenitis Syndrome. The Journal of Pediatrics, 159, 958-964. http://dx.doi.org/10.1016/j.jpeds.2011.06.004 
[5] Garavello, W., Pignataro, L., Gaini, L., Torretta, S., Somigliana, E. and Gaini, R. (2011) Tonsillectomy in Children with Periodic Fever with Aphthous Stomatitis, Pharyngitis, and Adenitis Syndrome. The Journal of Pediatrics, 159, 138-142. http://dx.doi.org/10.1016/j.jpeds.2010.12.014

[6] Stojanov, S., Hoffmann, F., Kery, A., Renner, E.D., Hartl, D., Lohse, P., Huss, K., Fraunberger, P., Malley, J.D., Zellerer, S., Albert, M.H. and Belohradsky, B.H. (2006) Cytokine Profile in PFAPA Syndrome Suggests Continuous Inflammation and Reduced Anti-Inflammatory Response. European Cytokine Network, 17, 90-97.

[7] Peridis, S., Koudoumnakis, E., Theodoridis, A., Stefanaki, K., Helmis, G. and Houlakis, M. (2010) Surgical Outcomes and Histology Findings after Tonsillectomy in Children with Periodic Fever, Aphthous Stomatitis, Pharyngitis, and Cervical Adenitis Syndrome. American Journal of Otolaryngology, 31, 472-475. http://dx.doi.org/10.1016/j.amjoto.2009.06.005

[8] Yamaguchi, H. (2011) Pediatric Infectious Disease and Kampo. Imminent Kampo Treatment for Childhood Disease, 10, 103-117. (Japanese)

[9] Ishii, A. (2013) Experiences of Shinbuto (Zhen-Wu-Tang, Chinese Herbal Medicine) for Acute Infections in Children. Nihon Shoni Toyo Igakkaishi, 25, 90-97. (Japanese with English Abstract) 
Scientific Research Publishing (SCIRP) is one of the largest Open Access journal publishers. It is currently publishing more than 200 open access, online, peer-reviewed journals covering a wide range of academic disciplines. SCIRP serves the worldwide academic communities and contributes to the progress and application of science with its publication.

Other selected journals from SCIRP are listed as below. Submit your manuscript to us via either submit@scirp.org or Online Submission Portal.
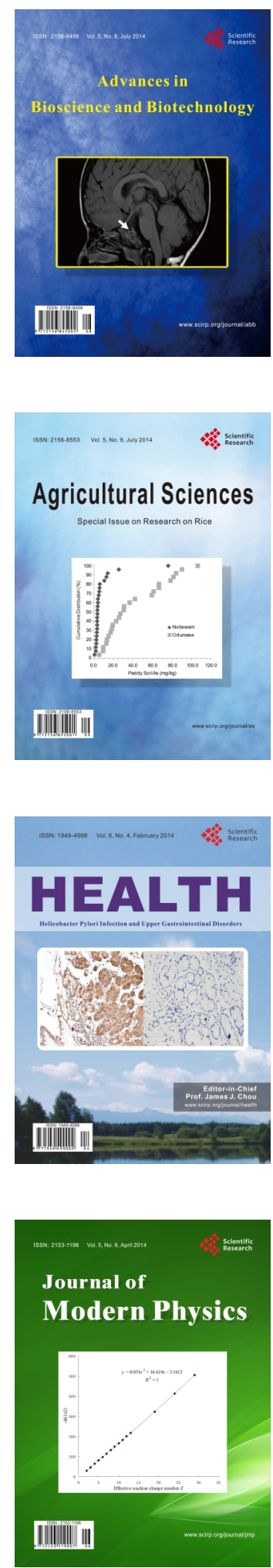
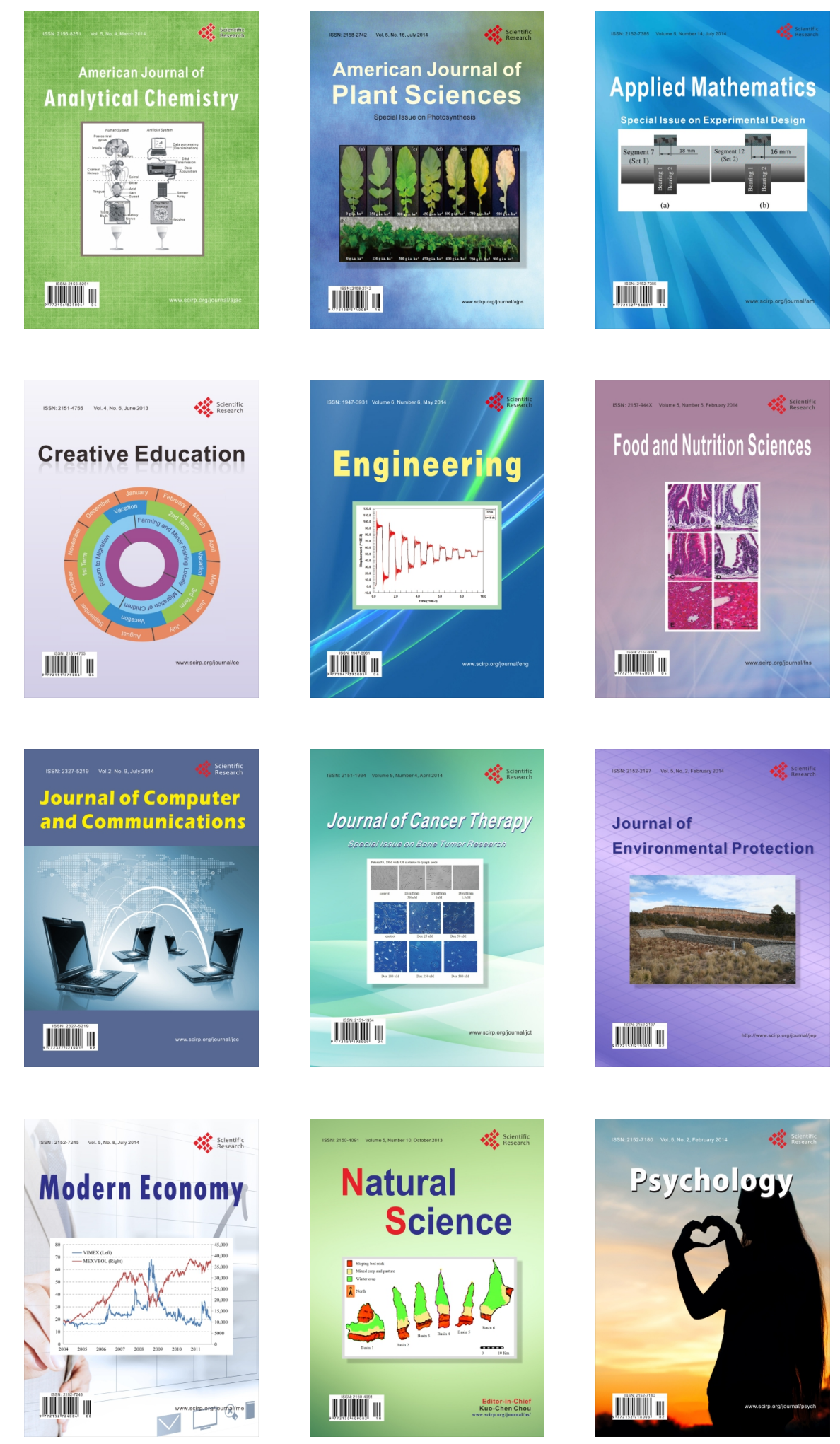